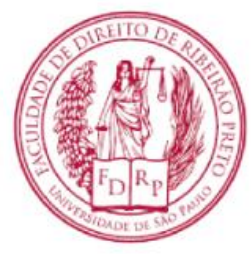

ReVista Digital De DiREITo AdMinistrativo

FACUldAdE DE DiREITO DE RiBEIRÃo PRETO - FDRP

UNIVERSIDADE DE SÃo PAULO - USP

Seção: Artigos Científicos

\title{
A separação dos Poderes e o controle jurisdicional da transparência das Políticas Públicas de Enfretamento ao Coronavírus no Brasil: exame da constitucionalidade do julgamento do Supremo Tribunal Fe- deral, na arguição de descumprimento de Preceito Fundamental no 690-DF, que estabeleceu o conteúdo da publicidade das informações sobre a Covid-19
}

The division of Powers and jurisdictional control of the transparency of Public Policies to Fight Against Coronavirus in Brazil: constitutionality examination of Supreme Court Judgement, in adpf 690-DF, that established the information publicity content about covid-19

Horácio Augusto Mendes de Sousa; Daury Cesar Fabriz

\begin{abstract}
Resumo: 0 presente artigo visa analisar a constitucionalidade do julgamento proferido pelo Supremo Tribunal Federal, na Arguição de Descumprimento de Preceito Fundamental no 690-DF, que estabeleceu a obrigatoriedade da transparência das informações sobre a Covid-19, à luz do princípio constitucional da separação e independência dos Poderes da República. Neste sentido, o problema da presente pesquisa consiste em analisar se a Suprema Corte pode interferir dessa maneira nas políticas de saúde formuladas pelo Poder Executivo Federal. Neste contexto, é importante identificar a tensão existente entre a deliberação do Poder Executivo Federal e a decisão do Supremo Tribunal Federal, bem como verificar como a Suprema Corte brasileira vem controlando a transparência das políticas públicas federais de enfretamento à Covid-19, visando à proteção direitos fundamentais.
\end{abstract}

Palavras-chave: Separação de Poderes; Controle; Políticas Públicas; Direitos fundamentais; Coronavírus.

\begin{abstract}
This article aims to analyze the constitutionality of the judgment headed by brazilian Supreme Court, in ADPF 690-DF, which established the mandatory transparency of information about Covid-19, in light of the constitutional principle of division and independence of the Republic Powers. The present research problem is to analyze if the brazilian Supreme Court can interfere in this magnitude on the Union health policies. In this context, it is important to identify the tension between Union and Supreme Court decisions, as well as to verify how this Court has been controlling the transparency of federal public policies to confront Covid-19, aiming the fundamental rights protection.
\end{abstract}

Keywords: Division of Powers; Control; Public policy; Fundamental rights; Coronavirus.

Disponível no URL: www.revistas.usp.br/rdda

DOI: http://dx.doi.org/10.11606/issn.2319-0558.v9n1p66-86 
REVISTA DIGITAL DE DIREITO ADMINISTRATIVO, vol. 9, n. 1, p. 66-86, 2022.

A SEPARAÇÃO dOS PODERES E O CONTROLE JURISDICIONAL DA TRANSPARÊNCIA DAS POLÍTICAS PÚBLICAS DE ENFRETAMENTO AO CORONAVÍRUS NO BRASIL: EXAME DA CONSTITUCIONALIDADE DO JULGAMENTO DO SUPREMO TRIBUNAL FEDERAL, NA ARGUIÇÃO DE DESCUMPRIMENTO DE PRECEITO FUNDAMENTAL № 690-DF, QUE ESTABELECEU O CONTEÚDO DA PUBLICIDADE DAS INFORMAÇÕES SOBRE A COVID-19

Horácio Augusto Mendes de SOUSA*; Daury Cesar FABRIZ**

Sumário: 1. Introdução; 2. O princípio da separação e independência dos Poderes no Direito brasileiro e o controle jurisdicional da transparência das políticas públicas para o enfretamento à Covid19; 3. Exame da constitucionalidade do julgamento do Supremo Tribunal Federal que estabeleceu a obrigatoriedade, a forma e o conteúdo da publicidade das informações sobre a Covid-19, nos autos da Arguição de Descumprimento de Preceito Fundamental no 690-DF, à luz do princípio constitucional da separação e independência dos Poderes; 4. Considerações finais; 5. Referências bibliográficas.

\section{Introdução}

0 presente artigo tem por finalidade analisar a constitucionalidade do julgamento proferido pelo Supremo Tribunal Federal, nos autos do processo pertinente à Arguição de Descumprimento de Preceito Fundamental no 690-DF, Relator Ministro Alexandre de Moraes, que estabeleceu a obrigatoriedade, a forma e o conteúdo da transparência das informações sobre a Covid-19 no Brasil, à luz do princípio constitucional da separação e independência dos Poderes da República.

O tema se reveste de relevância e atualidade, porque o Coronavírus, com a sua "cruel pedagogia" (SANTOS, 2020, p. 26-28), já matou muitas pessoas no Brasil, e continua

\footnotetext{
*Doutorando em Direitos e Garantias Fundamentais pela Faculdade de Direito de Vitória (FDV). Mestre em Direito Empresarial pela Universidade Candido Mendes (UCAM). Especialista em Economia e Direito do Consumidor pela Universidad Castilla La Mancha - Espanha. Membro do Grupo de Pesquisa Estado, Democracia Constitucional e Direitos Fundamentais, do Programa de Pós-Graduação Stricto Sensu em Direito da FDV. Professor convidado da Pós-Graduação da Faculdade de Direito de Vitória (FDV), da PósGraduação da Fundação Getúlio Vargas (FGV-RJ), da Pós-Graduação da Universidade do Estado do Rio de Janeiro (UERJ) e da Pós-Graduação da Escola Superior da Procuradoria Geral do Estado do Espírito Santo (ESPGE). Procurador do Estado do Espírito Santo.

**Doutor e Mestre em Direito Constitucional pela Faculdade de Direito da UFMG. Ex-Professor Adjunto da Faculdade de Direito da UFMG. Professor Associado do Departamento de Direito da UFES. Professor da Faculdade de Direito de Vitória-FDV (Graduação, Mestrado e Doutorado). Presidente da Academia Brasileira de Direitos Humanos-ABDH. Advogado.
} 
fulminando as vidas de muitos brasileiros, agravando, ainda mais, as crises sociais, econômicas, políticas e jurídicas vivenciadas pela sociedade brasileira nos últimos anos. Esse quadro reforça a importância da divulgação e transparência dos dados e números pertinentes à Covid-19, de modo a promover maior informação e conscientização dos cidadãos, bem como viabilizar a melhor formulação, planejamento, orçamentação, implementação e controle de políticas públicas de enfretamento dessa doença pandêmica.

Neste contexto, o Supremo Tribunal Federal, no precedente acima mencionado, impôs que a União Federal, por intermédio do Ministério da Saúde, veiculasse, por meio de determinada forma e conteúdo, estabelecida no julgado, as informações e dados a respeito da evolução da Covid-19 no Brasil, sob a argumentação jurídica central no sentido da necessidade de proteção dos direitos fundamentais à vida e à saúde dos cidadãos, razões pelas quais a adequada publicidade das informações pertinentes ao Coronavírus no Brasil seria essencial para o alcance desses objetivos citados.

Neste sentido, o problema da presente pesquisa consiste em analisar se a Suprema Corte brasileira pode determinar, ao Poder Executivo Federal, a obrigatoriedade, a forma e o conteúdo da publicidade pertinente aos dados e informações sobre a Covid-19, à luz do princípio da separação e independência dos Poderes, consagrado no artigo $2^{\circ}$ da Constituição da República Federativa do Brasil de 1988.

Como hipótese da presente pesquisa, admite-se, com certas cautelas jurídicas, que o Supremo Tribunal Federal possa determinar a forma e o conteúdo da publicidade inerente aos dados e informações relacionados à evolução da Covid-19 no Brasil, sob a argumentação jurídica, em especial, de proteção dos direitos fundamentais à vida, à saúde e à informação dos cidadãos.

Assim, objetiva-se identificar a tensão existe entre a deliberação do Poder Executivo Federal e a decisão do Supremo Tribunal Federal, bem como verificar como a Suprema Corte brasileira vem controlando a transparência e a publicidade das políticas públicas federais de enfrentamento à Covid-19, de modo a se analisar como se resolveu o conflito, no caso concreto, nos autos da ADPF n 690-DF.

0 presente trabalho está dividido em duas partes. Na primeira parte, investiga-se o princípio constitucional da separação e independência dos Poderes, adotado no artigo 2ํㅡㄹ da Constituição da República Federativa do Brasil de 1988, na perspectiva do controle jurisdicional da transparência das políticas públicas para o enfretamento à Covid-19. Na segunda parte, analisa-se a constitucionalidade do julgamento do Supremo Tribunal Federal, que estabeleceu a obrigatoriedade, o conteúdo e a forma da publicação das informações sobre a Covid-19 no Brasil, nos autos da Arguição de Descumprimento de Preceito Fundamental no 690-DF. 


\section{O princípio da separação e independência dos poderes no direito} brasileiro e o controle jurisdicional da transparência das políticas públicas para o enfretamento à Covid-19

A separação e independência dos Poderes se apresenta, no constitucionalismo brasileiro, como princípio constitucional estruturante previsto no artigo $2^{\circ}$ da Constituição da República Federativa do Brasil de 1988. Daí a matriz constitucional estabelecer que são Poderes dotados de harmonia e independência recíprocas, os Poderes Legislativo, Executivo e Judiciário. Desse modo, projeta-se, no paradigma do Estado Democrático de Direito do Brasil, a diretriz normativa da modernidade, consagrada no artigo 16 da Declaração de Direitos do Homem e do Cidadão de 1789, segundo a qual "[...] a sociedade em que não esteja assegurada a garantia dos direitos nem estabelecida a separação dos poderes não tem Constituição"1.

Assim, diante da relevância político-jurídica da aludida norma, enquanto princípio de organização estrutural do Estado Constitucional (CANOTILHO, 1998, p. 513), o mesmo vem sendo revisitado contemporaneamente pela doutrina, notadamente na perspectiva do controle jurisdicional das políticas públicas, especialmente pela ascensão institucional do Poder Judiciário depois da Segunda Guerra Mundial, em um processo político-jurídico em permanente construção, como será visto adiante.

Destarte, segundo Alfonso De Julios-Campuzano, em lições aplicáveis ao princípio da separação e independência do Poderes, a "[...] gestação do sistema jurídico da modernidade" é um processo lento, gradual e desenvolvido no transcorrer dos séculos, com a incidência de vários fatores e condicionantes relacionadas ao exercício e à concentração de poder e que, com o transcorrer do tempo, vão conformando o fenômeno jurídico, dando ensejo à uma nova concepção do jurídico, mais consentânea com a nova ordem social, política e econômica (CAMPUZANO, 2018, p. 11-12).

Nada obstante esses fatores e circunstâncias moduladoras do fenômeno do poder no transcurso dos tempos, ainda segundo Alfonso De Julios Campuzano, na democracia constitucional, é essencial a ideia de contenção, pois “[...] não pode existir poder tão grande que não esteja submetido à limites e controles [...]", de modo que o poder político se constrói baseado no consenso, nos limites e no reconhecimento de direitos e garantias, conformando a democracia e o exercício dos poderes democráticos ao Direito (JULIOS-CAMPUZANO, 2019, p. 500-501).

Em lições pertinentes à democracia constitucional contemporânea, aplicáveis ao princípio da separação e independência de Poderes, Maurizio Fioravanti ressalta a necessidade de equilíbrio na relação entre os sujeitos da política democrática, nota-

1 Disponível em: http://www.direitoshumanos.usp.br/index.php/Documentos-anteriores-\%C3\%A0cria\%C3\%A7\%C3\%A3o-da-Sociedade-das-Na\%C3\%A7\%C3\%B5es-at\%C3\%A9-1919/declaracao-de-direitos-do-homem-e-do-cidadao-1789.html. Acesso em: 29 set. 2020. 
damente o parlamento e o governo, e os sujeitos de garantia jurisdicional, quais sejam, os juízes e Tribunais, de modo que a consolidação desse equilíbrio pressupõe que os mesmos percebam a tentação de invadir os campos de atuação dos outros, o que nem sempre acontece na vida real (FIORAVANTI, 2001, p. 163-164).

Neste contexto, o princípio jurídico-constitucional da separação e independência dos Poderes, verdadeira ratio essendi da Constituição (CANOTILHO, 1998, p. 513), tem por finalidade substancial disciplinar o exercício do poder político-jurídico, na sua perspectiva horizontal, considerando-se a necessária relação de autonomia, harmonia e interdependência, funcional e sistêmica, que deve existir entre os diversos núcleos orgânicos de Poder estatal.

E assim deve ser para que o próprio Estado atinja seus objetivos desenvolvimentistas previstos no artigo 3ํ da Constituição da República Federativa do Brasil de 1988, além do alcance dos seus fins específicos, como é o caso da promoção do direito fundamental à saúde (artigos 6º e 196 a 200).

Nessa perspectiva substancial, o princípio da separação e independência dos Poderes refere-se à diferenciação funcional entre as atividades legislativas, executivas e jurisdicionais, com a demarcação institucional das competências dos núcleos orgânicos de Poderes citados, assim como estabelece a relação de controle recíproco entre esses vários órgãos (CANOTILHO, 1998, p. 513). Essa diferenciação funcional se vincula, também, à necessidade de exercício especializado, adequado e predominante dessas funções pelos núcleos orgânicos de Poderes, embora sem caráter de exclusividade funcional. Daí se falar em "adequação funcional", o que pressupõe que esses órgãos sejam, sob a ótica estrutural, "constitucionalmente idôneos" e adequados para o exercício das missões que lhes são conferidas (CANOTILHO, 1998, p. 515).

Cuida-se, na lição de Diogo de Figueiredo Moreira Neto, de "vitoriosa fórmula política, destinada a incrementar a eficiência governamental pela especialização funcional e, simultaneamente, a promover o seu controle pela limitação do poder" (MOREIRA NETO, 2014, p. 66), a partir da sua adequada compartimentalização na Constituição.

Bem por isso, diante dessa multiplicidade de aspectos substanciais relevantes, José Joaquim Gomes Canotilho sustenta que se cuida de um "princípio estrutural-conformador do domínio político" (CANOTILHO, 1998, p. 514), no caso do Brasil, limitado pela Constituição brasileira de 1988 e direcionado ao alcance dos fins e missões do Estado, a partir do controle recíproco voltado ao equilíbrio entre os Poderes e à proteção dos direitos fundamentais dos cidadãos contra os abusos ou excessos dos mesmos Poderes. Daí porque, na visão do autor, esse princípio se desdobra em vários níveis: 
(1) no plano funcional, interessa identificar as funções político-constitucionais básicas como a legiferação, a jurisdição e a execução; (2) no plano institucional, a separação de "poderes" incide especialmente sobre os órgãos constitucionais, como, por ex., o parlamento, o governo e os tribunais; (3) a nível sociocultural, interessa articular o "poder" ou poderes do Estado com as estruturas sociais (grupos, classes, partidos) (CANOTILHO, 1998, p. 514).

Em outros termos, analisar o princípio da separação e independência dos Poderes perpassa pela verificação, sob a ótica funcional, dos limites e possibilidades constitucionais para o exercício das funções administrativas, legislativas e jurisdicionais, o que abrange a investigação a respeito das estruturas jurídicas de governança dessas funções e, especialmente, o exame dos aspectos jurídicos das relações entre os Poderes, os grupos sociais intermédios e os cidadãos, enquanto destinatários maiores de todas as ações do Estado.

Vale lembrar que essas análises devem ser dar no contexto de uma sociedade plural, complexa, crescentemente tecnológica, digital, global, de riscos e em crise, agravada pela Covid-19, cada vez mais ciente, consciente e exigente de políticas públicas eficientes e eficazes, notadamente no ordenamento constitucional setorial sensível da saúde pública (artigos 6ํㅡ e 196 a 200).

Neste contexto, a doutrina tem evidenciado, no âmbito das variadas crises do Estado contemporâneo, uma crise específica do princípio da separação e independência dos Poderes, afetando a sua própria funcionalidade, especialmente pela substituição das funções estatais nos espaços de exercício do poder, com destaque para a ascensão da função jurisdicional, enquanto função de garantia dos direitos fundamentais, notadamente a justiça constitucional, operando-se a judicialização da Política e a politização do Direito (MORAIS, 2011, p. 56-68). 0 tema será retomado adiante, ao tratarmos do controle jurisdicional da transparência das políticas públicas de saúde para combate à Covid-19.

Ademais disso, no complexo arranjo constitucional, com vistas ao equilíbrio entre os Poderes, destaca-se a necessidade de controle recíproco entre os mesmos, por meio do que se convencionou chamar de sistema de "freios e contrapesos", de modo a evitar a configuração de um "superpoder" e, consequentemente, a possibilidade de abusos e excessos em face dos demais Poderes, dos grupos sociais intermédios e dos cidadãos, obtendo-se, na maior medida possível, um "governo moderado", todavia, sem "esvaziamento material" total das funções de um órgão pelo outro, a pretexto de controle (CANOTILHO, 1998, p. 514-517).

Contemporaneamente, como dito acima, a doutrina tem proposto a revisão do princípio da separação e independência dos Poderes, notadamente porque ele não representa um modelo rígido e estático, mas um esquema primordial e básico, em outros termos, "um princípio organizatório fundamental", razão pela qual não há que 
se cogitar da sua "realização estrita" e, nem tampouco, esse princípio deve ser considerado como "um dogma de valor intertemporal" (CANOTILHO, 1998, p. 514).

Consoante ensina Luigi Ferrajoli, em sua formulação original, a separação de poderes somente se refere aos poderes públicos, mas, nos dias de hoje, diante da complexidade dos sistemas sociais, seja pela multiplicidade de poderes sujeitos à limites e controles, exigidos pelo paradigma constitucional, quer pela multiplicidade de direitos e bens constitucionalizados e suas correspondentes garantias, se impõe a necessidade de uma pluralidade de separações e equilíbrios entre os poderes, muito além da sua configuração tríplice clássica, de modo a abranger uma separação entre poderes políticos, econômicos, sociais e poderes públicos inseridos na esfera pública propriamente dita (FERRAJOLI, 2014, p. 183-185).

Na lição de Isidre Molas, a concepção moderna de separação de Poderes ou funções estatais abrange tanto as ideias de equilíbrio e colaboração entre as instituições do Estado, como, também, o mesmo equilíbrio e colaboração entre os poderes estatais e as diversificadas e plurais classes sociais e segmentos intermédios da sociedade (MOLAS, 2008, p. 50).

Neste sentido, consoante ensina Diogo de Figueiredo Moreira Neto, ocorre a necessidade de releitura contemporânea do princípio em tela, especialmente porque a sua configuração clássica tripartite não conseguiu proteger as sociedades das "autocracias absolutas", que se expandiram no século XX e ensejaram o cenário propício aos horrores dos regimes fascistas e nazistas, com a "hipertrofia patológica dos governantes", cujas consequências drásticas foram as duas grandes guerras mundiais, seguidas de um guerra-fria, "exaurindo aquela ingênua confiança nos modelos experimentados na Modernidade" (MOREIRA NETO, 2014, p. 67-68).

Assim, com a insuficiência do controle político por meio dos processos eletivos, surge a necessidade de ampliação dos canais de participação do cidadão, especialmente os de controle, dando ensejo ao surgimento de variadas e novas funções constitucionalmente autônomas, de forma paralela e complementar às clássicas funções legislativas, executivas e jurisdicionais. Na lição do autor:

[...] Esse novo modelo deveria multiplicar e aperfeiçoar os canais participativos da cidadania, notadamente os de controle, instituindo, para este efeito, uma série de novas funções constitucionalmente independentes, em paralelo e complementarmente às funções dos "três poderes" tradicionais, para passarem a atuar como extensões da sociedade inseridas no próprio aparelho de Estado, portanto, como órgãos híbridos, agindo independentemente, mas harmonicamente com as demais funções de Estado (MOREIRA NETO, 2014, p. 69).

Neste passo, tem-se configurado esse movimento revisionista do princípio em exame, a começar pela sua própria nomenclatura, já que o Poder é único e indivisível, na forma do artigo 1ํㅡ, parágrafo único da Constituição brasileira de 1988, de 
modo que a separação orgânica que ocorre, no paradigma do Estado Democrático de Direito adotado no Brasil, é funcional. Do mesmo modo, é correto dizer, também, que essas funções não se esgotam no modelo de repartição tríplice, destacando-se outras funções constitucionalmente relevantes e autônomas (MOREIRA NETO, 2014, p. 76-84). Logo, parece mais apropriado se falar em separação de funções estatais, que não se limitariam às três clássicas, no constitucionalismo Democrático de Direito adotado no Brasil. Todavia, como a Constituição brasileira de 1988 utiliza a expressão "poderes" (artigo $2^{\circ}$ ), feita a ressalva acima, será utilizado o termo "separação de poderes", com o sentido de "separação de funções estatais".

Daí porque Diogo de Figueiredo Moreira Neto vai sustentar a necessidade de consolidação das "funções neutrais", na perspectiva político-partidária, diferente das funções de governo e parlamentares, que substancialmente expressam segmentos político-partidários. Essas funções constitucionais, dotadas de neutralidade políticopartidária, têm a missão de proteger e promover os valores fundantes, gerais e permanentes da sociedade, como os direitos fundamentais, distintamente das funções administrativas e legislativas, que não são gerais, por expressam interesses de grupos, e, nem tampouco, permanentes, pois, por serem parciais, "são voláteis como os grupos que os sustentam" (MOREIRA NETO, 2014, p. 70).

Dentre essas funções constitucionais dotadas de neutralidade político-partidária, embora clássica, mas com importância para o presente estudo, destaca-se o Poder Judiciário, notadamente o Supremo Tribunal Federal, que vem exercendo intenso controle jurisdicional sobre a transparência das políticas públicas de saúde diante da Covid-19. Daí por que o estudo do controle jurisdicional das políticas públicas tem sido objeto de preocupações por parte da doutrina.

Consoante ensina Diogo de Figueiredo Moreira Neto, como o Estado e o Direito devem respeito e máxima observância à Constituição, entendida como "estatuto do poder estatal dotado de máxima normatividade", toda ação estatal, em qualquer nível das atividades e funções desempenhadas pelos dos órgãos estatais, só terá validade se vinculada à normatividade constitucional (MOREIRA NETO, 2016, p. 90). Na síntese de Miguel Sánches Morón, a submissão plena da administração pública à lei e ao Direito é uma cláusula primordial do Estado de Direito (MORÓN, 2008, p. 84).

Prossegue o autor dizendo que a lógica do controle sobre a ação administrativa, a partir da concepção clássica da "separação de Poderes", decorrente do modelo revolucionário francês, era centrada na legalidade objetiva, que significava assegurar a observância da lei pela administração pública, e passou a contemplar um controle de legalidade subjetiva, de modo a assegurar a tutela efetiva de direitos subjetivos dos cidadãos (MOREIRA NETO, 2016, p. 90), incluindo-se, nesta perspectiva, a proteção e promoção dos direitos fundamentais. Na lição de Eduardo García de Enterría: 
Os direitos que o cidadão detém na complexa sociedade atual, direitos que incluem o assaz essencial direito de não poder ser afetado, em seus interesses materiais e morais de sua existência, sobre o qual se constrói sua posição essencial de homem livre e independente, a não ser em virtude da lei, estabeleceu a necessidade de estes serem protegidos, de maneira eficaz, caso tais interesses se encontrem afetados por uma atuação administrativa ilegal (GARCÍA DE ENTERRÍA, 2017, p. 106).

Neste contexto, assevera Miguel Seabra Fagundes, ao destacar que o controle jurisdicional da administração pública se destina, substancialmente, à proteção do cidadão em face desse mesmo Estado-administrador (FAGUNDES, 2006, p. 135-136).

Ainda na linha evolutiva do controle sobre a ação administrativa estatal, esse deixa de incidir somente sobre a legalidade objetiva e subjetiva do ato administrativo, ampliando-se para o controle dos atos administrativos, necessariamente praticados no âmbito devido processo legal, até se chegar, contemporaneamente, ao controle das políticas públicas, enquanto complexo de processos jurídico-políticos e administrativos (MOREIRA NETO, 2016, p. 91), mais adiante, definidas pelo autor, como: "0 complexo de processos destinados a realizar, de modo coerente o coordenado, as decisões políticas setoriais do Estado e do Governo" (MOREIRA NETO, 2018, p. 209).

Essa ideia de procedimentalização de todo o atuar do Estado, notadamente na perspectiva da administração dos complexos interesses públicos, também é destacada por Paulo Otero, ao asseverar que o "[...] procedimento consubstancia uma forma de juridificação paramétrica da vontade do Poder, condicionando-a;" (OTERO, 2019, p. 21-22).

No mesmo sentido, Odete Medauar vai aludir à importância da processualidade administrativa como meio para que os diversos interesses públicos, em uma sociedade plural e complexa, aflorem antes da tomada de decisões, viabilizando o controle de cidadãos e grupos intermédios sobre o exercício das funções administrativas do Estado (MEDAUAR, 2003, p. 224-225).

Neste passo, o controle das políticas públicas, entendidas como o devido processo legal, constitucionalmente delimitado, voltado à formulação, planejamento, orçamentação, implementação e controle das ações estatais, com vistas ao alcance dos objetivos constitucionais gerais da República brasileira (artigo $3^{\circ}$ ) e, em especial, à promoção dos direitos fundamentais, amplia-se para alcançar o exame de manifestação da vontade administrativa sob o prisma da legalidade, simultaneamente à análise da "efetividade da vontade administrativa", no que tange aos seus resultados esperados e alcançados, ou seja, o "efetivo atendimento dos cometimentos e condicionamentos constitucionalmente impostos ao Estado" (MOREIRA NETO, 2016, p. 92). Na síntese do autor: 
[...] o controle de resultado se afigura muito mais abrangente, pois, além da aplicação dos parâmetros tradicionais sobre a manifestação da vontade administrativa, admite e pede a formulação de novos parâmetros, como os de legitimidade, de moralidade e de eficiência, inclusive no que toca ao atendimento de normas técnicas, tão importante na civilização atual altamente demandante de tecnologia (MOREIRA NETO, 2016, p. 92).

Esse controle de resultados das políticas públicas é plenamente compatível com a Constituição brasileira de 1988, pois visa concretizar, em especial, os princípios constitucionais da eficiência e eficácia das atividades administrativas estatais (artigos 37 e 74), de modo a verificar a concretização, real e prática, do direito fundamental à boa administração pública, o que pressupõe, na lição de Juarez Freitas, uma gestão pública:

[...] eficiente e eficaz, proporcional cumpridora de seus deveres, com transparência, sustentabilidade, motivação proporcional, imparcialidade e respeito à moralidade, à participação social e à plena responsabilidade por suas condutas omissivas e comissivas (FREITAS, 2014, p. 21).

Diante da ampliação da importância do controle jurisdicional das políticas públicas no Brasil, e de modo a conformá-lo ao princípio da separação e independência das funções estatais, e tendo em vista a ocorrência de excessos, em algumas oportunidades, por parte dos órgãos do controle, foi editada a Lei no 13.655, de 25 de abril de 2018, que estabelece um conjunto relevante de normas disciplinadoras da atividade controladora no Brasil. A finalidade da normatividade mencionada é conferir maior segurança jurídica e eficiência para as decisões dos gestores públicos e dos órgãos de controle. Assim, a lei viabiliza a necessária distinção entre o bom e o mau gestor público, de modo que o primeiro tenha proteção para exercer, de maneira eficiente e eficaz, as suas missões, ao passo que o segundo seja gravemente sancionado pelos seus ilícitos ímprobos.

Nas lições de Floriano de Azevedo Marques Neto e Rafael Véras de Freitas, a normatividade em perspectiva tem por finalidade precípua a realização da segurança jurídica, nas suas vertentes de estabilidade, previsibilidade, proporcionalidade e ponderabilidade, no âmbito da criação, interpretação e aplicação das normas de Direito Público no Brasil (FREITAS e MARQUES NETO, 2019, p. 18).

A normatividade em exame se justifica, portanto, porque é incontroverso que o Estado brasileiro precisa incrementar substancialmente os resultados de suas prestações e entregas à sociedade, de modo a cumprir às suas respectivas missões constitucionais desenvolvimentistas do Estado Democrático de Direito brasileiro consagradas na Constituição brasileira de 1988 (artigo 3ํㅜ). Daí porque a lei mencionada reforça a necessidade de observância de princípios constitucionais como os 
da segurança jurídica, eficiência, razoabilidade, proporcionalidade e eficácia dos resultados das ações estatais (SOUSA, 2019, p. 195-216).

Neste contexto, o controle jurisdicional de políticas públicas de saúde para o enfretamento à Covid-19 no Brasil tem ocorrido com grande intensidade, inclusive no âmbito da jurisprudência do Supremo Tribunal Federal, especialmente no que tange à necessidade de adequada publicidade, informação e transparência das políticas públicas de combate ao Coronavírus, objeto específico do presente estudo.

Como exemplo, vale mencionar a decisão proferida pelo Supremo Tribunal Federal, nos autos do processo referente à Arguição de Descumprimento de Preceito Fundamental no 669-DF, Relator Ministro Luís Roberto Barroso, proposta por partido político em face União Federal. A ação constitucional mencionada tinha por objeto obstar a contratação e divulgação de campanha publicitária, pela União Federal, baseada na mensagem "O Brasil não pode parar", de modo a convocar a população brasileira a retomar as suas atividades sociais e econômicas normais, mesmo diante da atual crise pandêmica do Coronavírus, com consequências gravíssimas no Brasil.

Diante disso, a Suprema Corte brasileira proibiu que a União Federal venha a veicular qualquer publicidade institucional direcionada a induzir a população brasileira ao retorno normal às suas atividades, interditando ao Poder Executivo Federal a realização de qualquer campanha publicitária direcionada a informar à população que a pandemia constitui evento de menor gravidade para a vida e a saúde da população brasileira, proibindo-se a realização de contratação de campanha publicitária destinada à mesma finalidade.

No caso concreto, o Supremo Tribunal Federal utilizou a argumentação jurídica no sentido de que essa política pública vulneraria os direitos fundamentais à vida (ar-

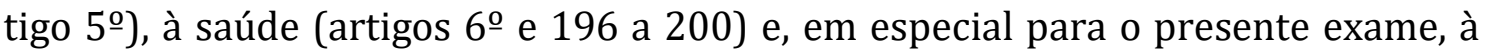
informação dos cidadãos (artigos 5ㅜㅡ. XXXIII e 37), tendo em vista que a publicidade citada geraria verdadeira desinformação às pessoas, colocando em risco os direitos fundamentais aludidos, estando em desacordo, ainda, com as orientações da Organização Mundial da Saúde e do Conselho Federal de Medicina do Brasil, ambas as entidades recomendando o isolamento e distanciamento sociais como medidas para a contenção da proliferação da Covid-19.

Destarte, no contexto da Covid-19, a separação das funções estatais, diante da Constituição da República Federativa do Brasil de 1988, significa o exercício prudente, razoável, proporcional, equilibrado e moderado, das respectivas funções especializadas, pelos órgãos constitucionalmente autônomos. Essas devem ser dar em harmonia com os demais núcleos orgânicos de funções estatais, de modo a realizar, de maneira eficiente e eficaz, a formulação, planejamento, orçamentação, implementação e controle das políticas públicas de saúde pública, concretizando o direito fundamental à boa administração pública, na perspectiva do direito fundamental à saúde, a partir da prestação adequada dos serviços públicos de saúde, que pressupõe 
ações estatais visíveis e transparentes, em consonância com as diretrizes da comunidade científica.

Neste sentido, a não observância desses parâmetros constitucionais para a eficiente e eficaz prestação dos serviços públicos de saúde viabiliza e justifica constitucionalmente a intervenção, razoável e proporcional, do Poder Judiciário, no controle das políticas públicas de saúde, de modo a conformá-las aos limites e possibilidades fixados na Constituição da República de 1988, com vistas a resguardar o direito fundamental à saúde dos cidadãos, diante da crise pandêmica da Covid-19, sem que se tenha violação ao princípio constitucional da separação das funções estatais previsto no artigo 2o da Constituição da República Federativa do Brasil de 1988.

No próximo capítulo, com base nos aportes teóricos do presente capítulo, analisa-se a constitucionalidade do julgamento proferido pelo Supremo Tribunal Federal, nos autos do processo pertinente à Arguição de Descumprimento de Preceito Fundamental no 690-DF, Relator Ministro Alexandre de Moraes, que estabeleceu a obrigatoriedade, a forma e o conteúdo da transparência das informações sobre a Covid-19 no Brasil, à luz do princípio constitucional da separação e independência dos Poderes da República.

\section{Exame da constitucionalidade do julgamento do Supremo Tribunal}

Federal que estabeleceu a obrigatoriedade, a forma e o conteúdo da publicidade das informações sobre a Covid-19, nos autos da Arguição de Descumprimento de Preceito Fundamental no 690-DF, à luz do princípio constitucional da separação e independência dos poderes

Como adiantado no capítulo anterior, o presente capítulo visa analisar a constitucionalidade do julgamento proferido pelo Supremo Tribunal Federal, nos autos do processo pertinente à Arguição de Descumprimento de Preceito Fundamental no 690-DF, Relator Ministro Alexandre de Moraes, que estabeleceu a obrigatoriedade, a forma e o conteúdo da transparência das informações sobre a Covid-19 no Brasil.

Assim, cabe verificar se a Suprema Corte brasileira pode determinar, ao Poder Executivo Federal, a obrigatoriedade, a forma e o conteúdo da publicidade pertinente aos dados e informações sobre a Covid-19, à luz do princípio da separação e independência dos Poderes, consagrado no artigo $2^{\circ}$ da Constituição da República Federativa do Brasil de 1988.

O caso concreto cuidava de ação constitucional, proposta por partidos políticos, em face da União Federal, em razão de condutas do Poder Executivo Federal, concretizadas na prática de atos que modificaram e restringiram a publicidade dos dados e informações públicas pertinentes à evolução e enfrentamento da Covid-19 no Brasil. Essas condutas, segundo os autores, se concretizaram em atrasos nas divulgações 
dos dados, alterações do formato da divulgação dos dados, omissão de dados relevantes, retirada, do sítio institucional do Ministério da Saúde, dos dados diários sobre o Coronavírus e a modificação do aplicativo "Coronavírus-SUS", com a omissão de dados sobre a evolução da Covid-19 no Brasil.

Assim, segundo os autores, a mudança de práticas e rotinas na divulgação dos dados sobre o Coronavírus, bem como a retenção de dados de interesse público, torna inviável o acompanhamento da execução das políticas públicas sanitárias para o enfrentamento da pandemia, em violação aos direitos fundamentais à vida, à saúde, à transparência e ao interesse público na correta divulgação dos dados e informações de interesse da sociedade. Por tais razões, postularam a adequada e transparente divulgação dos dados, com ampla publicidade dos mesmos.

O Supremo Tribunal Federal, em sede cautelar, concedeu parcialmente a medida, e, posteriormente, no mérito, decidiu no sentido de determinar à União Federal, por meio do Ministro da Saúde, a manutenção integral da divulgação diária dos dados relativos à Covid-19, inclusive no sítio institucional do Ministério da Saúde, com os números acumulados de ocorrências, como era feito pelo aludido órgão, até o dia 04 de junho de 2020.

Na oportunidade, a Suprema Corte utilizou como argumentos jurídicos, em síntese, a necessidade de proteção dos direitos fundamentais à vida, à saúde e à informação dos cidadãos, por meio de adequadas políticas públicas de saúde, como projeções do princípio constitucional da dignidade da pessoa humana, e que poderiam ser gravemente comprometidos, no contexto de enfretamento à Covid-19 no Brasil, caso as informações e dados sobre a pandemia não fossem divulgados adequadamente.

Destacou o julgado, também, a necessidade de respeito ao princípio constitucional da publicidade dos atos administrativos e das políticas públicas, como obrigação constitucional decorrente do sistema único de saúde e que encontra respaldo na comunidade científica internacional e em suas boas práticas de coleta, armazenamento, gestão e divulgação dos dados sobre o Coronavírus, com vistas ao planejamento de políticas públicas adequadas diante da crise sanitária.

Neste sentido, sob a ótica do direito constitucional internacional, não se cuida de uma importação acrítica de diretrizes adotadas internacionalmente, mas, sim, do acolhimento de recomendações técnico-científicas, no âmbito da cooperação entre os Estados soberanos, lastreada no artigo 4ํ da Constituição da República de 1988.

Neste contexto, como se sabe, cabe aos Poderes Executivo e Legislativo, na forma da Constituição brasileira de 1988 (artigo 84, inciso XI), precipuamente, a formulação, o planejamento, a orçamentação e a execução das políticas públicas de saúde, cabendo ao Poder Judiciário o controle de constitucionalidade e legalidade das mesmas (MOREIRA NETO, 2018, p. 209). 
Assim, em linha de princípio, seria vedado ao Poder Judiciário determinar a obrigatoriedade, a forma e o conteúdo da publicidade pertinente às políticas públicas de saúde para o enfretamento ao Coronavírus, incluindo-se, nesta perspectiva, o conteúdo e a forma de veiculação à população dos dados e informações pertinentes à pandemia, eis que se cuida de atividade tipicamente administrativa, cuja gestão cabe ao Chefe do Poder Executivo Federal, no exercício da direção superior da administração pública, podendo contar com o auxílio dos seus Ministros, nos termos da mesma Constituição brasileira de 1988 (artigo 84, inciso II).

Neste sentido, a atuação discricionária do Poder Executivo, dentro dos limites fixados pela Constituição e pelo Direito, de maneira proporcional, não autoriza a substituição da decisão do gestor público pela decisão dos órgãos de controle, por força do princípio da deferência, decorrente do princípio da separação de poderes ora estudado.

No âmbito das políticas públicas emergenciais de saúde para o enfretamento à Covid-19, foi editada a Lei no 13.979 , de 06 de fevereiro de 2020, que estabelece medidas de enfrentamento à pandemia. Assim, ao fixar algumas medidas restritivas de direitos e liberdades dos cidadãos, por um lado, a normatividade previu, por outro lado, que as ações e políticas públicas só poderiam ser formuladas e executadas com base em "evidências científicas e em análises sobre as informações estratégicas em saúde", assegurando-se às pessoas "[...] o direito de serem informadas permanentemente sobre o seu estado de saúde e a assistência à família", sem prejuízo do pleno e integral acatamento e "respeito à dignidade, aos direitos humanos e às liberdades

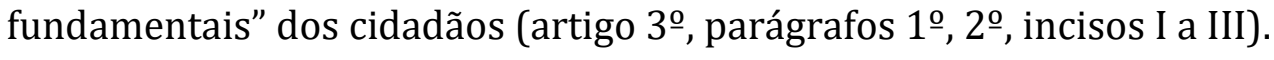

Ainda na perspectiva concretizadora do direito fundamental à informação (artigo 5ำ XXXIII) e dos princípios da publicidade e transparência das políticas públicas de saúde (artigo 37), nos termos da Constituição brasileira de 1988, a normatividade emergencial em análise estabeleceu a obrigatoriedade do compartilhamento entre os entes da Federação brasileira, bem como todas as pessoas jurídicas de Direito Privado, quando solicitadas, dos dados essenciais para a identificação de pessoas infectadas ou com suspeita de infecção, com a finalidade específica e exclusiva de se evitar a proliferação do vírus, nos termos do artigo 6oㅡ, parágrafo $1^{0}$, da Lei $\mathrm{n}^{\mathrm{o}}$ $13.979 / 2020$.

Vale destacar, também, em especial para o presente exame, a obrigação de a União Federal, por meio do Ministério da Saúde, manter "dados públicos e atualizados sobre os casos confirmados, suspeitos e em investigação, relativos à situação de emergência pública sanitária, resguardando o direito ao sigilo das informações pessoais", nos termos do artigo 6º parágrafo $2^{\circ}$ da Lei n 13.979/2020. Cuida-se, pois, de normatividade concretizadora do princípio constitucional da publicidade que, na lição de Diogo de Figueiredo Moreira Neto: 
[...] o princípio da publicidade assoma como o mais importante princípio instrumental e condição indispensável para a sindicabilidade da legalidade, da legitimidade, e da moralidade da ação do Poder Público, pois será a transparência dos seus atos, ou, como mais adequadamente expressado, por sua visibilidade, que se tornará possível constatar a sua conformidade ou desconformidade com a ordem jurídica e, em consequência, poderem ser exercidas as várias modalidades de controle nela previstos. [...] constitui-se também como um direito fundamental do administrado, extensivo às entidades de sua criação, uma vez que, sem ela, não passaria de uma falácia a sustentação dos direitos fundamentais e do próprio Estado de Direito (MOREIRA NETO, 2006, p. 278).

Neste sentido, a determinação judicial em análise se reveste de razoabilidade e proporcionalidade, porque os meios utilizados (divulgação ampla de dados sobre a Covid-19) são adequados aos fins pretendidos (informação, conscientização da população e viabilização do controle das políticas públicas de enfretamento à pandemia).

Ademais, as medidas são necessárias e exigíveis para o resguardo dos direitos fundamentais à vida, à saúde e à informação dos cidadãos, conferindo proteção adequada aos bens jurídicos tutelados, na perspectiva da publicidade, sem constituir ônus desproporcional à União Federal, que já adotava essa forma de divulgação de conteúdo para a publicidade anteriormente praticada. Bem por isso, a decisão também se reveste de proporcionalidade em sentido restrito, pois os direitos fundamentais protegidos, acima explicitados, reforçam o equilíbrio da decisão na relação entre benefícios pretendidos e custos e malefícios decorrentes da mesma decisão.

A deferência jurisdicional às políticas públicas formuladas pelas instâncias políticomajoritárias, algumas vezes inobservada pelo Poder Judiciário, pressupõe que a discricionariedade administrativa seja exercida com respeito aos limites constitucionais, dentre eles, o direito fundamental à informação e à necessária visibilidade e racionalidade técnica das decisões estatais com fulcro em dados acessíveis e transparentes, em um contexto de governança pública cada vez mais orientada por standards e indicadores científicos (SOUSA, 2020, p. 63-102).

Neste passo, a visibilidade, transparência e acessibilidade dos dados decorrentes da crise pandêmica do Coronavírus constitui pressuposto crucial para o eficiente funcionamento do sistema único de saúde, em bases coordenadas e sistêmicas, na forma do artigo 198 da Constituição da República de 1988, assim como parâmetros para o controle e sindicabilidade das políticas públicas adotadas. Segundo o Supremo Tribunal Federal, nos autos da ADPF no 690-DF ora em análise:

2. A gravidade da emergência causada pela COVID-19 exige das autoridades brasileiras, em todos os níveis de governo, a efetivação concreta da proteção à saúde pública, com a adoção de todas as medidas possíveis para o apoio e manutenção das atividades do Sistema 
Único de Saúde, entre elas o fornecimento de todas as informações necessárias para o planejamento e o combate à pandemia. 3. 0 risco decorrente da interrupção abrupta da coleta e divulgação de informações epidemiológicas, imprescindíveis para a análise da série histórica de evolução da pandemia (COVID-19), fundamenta a manutenção da divulgação integral de todos os dados que o Ministério da Saúde realizou até 4 de junho 2020, e o Governo do Distrito Federal até 18 de agosto passado, sob pena de dano irreparável (BRASIL, Supremo Tribunal Federal, 2020).

Essa tecnicidade é essencial na formulação, implementação e controle das políticas públicas de saúde, notadamente no contexto da Covid-19, onde a relevância da consideração dos dados e evidências científicas foi reforçada no já citado artigo $3^{\circ}$, $§ 1^{\circ}$, da Lei nº 13.979/2020 (BUSSINGUER e SOUSA, 2020, p. 265-294).

Até porque, se cuidam de dados básicos, como os números de casos confirmados, de óbitos, de recuperados, dentre outras informações substanciais, não se vislumbrando escusa plausível para publicidade que não contemple essas informações essenciais para os cidadãos e órgãos de controle. Significa dizer, cuida-se de intervenção judicial razoável e proporcional para a proteção e promoção dos direitos fundamentais à vida, à saúde e à informação da população brasileira, por meio de publicidade ampla e transparente dos dados informações pertinentes a Covid-19.

Nas lições de Maria Lírida Calou de Araújo e Mendonça e Francisca Pequena:

Na Administração Pública não existe somente a necessidade de tornar públicos os atos praticados pelos órgãos, mas também a obrigação de dar transparência, sendo relevante que os indivíduos tenham acesso às redes de comunicação e de informação, uma vez que o dever de transparência é próprio do direito humano à informação. Nesse aspecto, a atuação do Estado e da Sociedade deve ocorrer de forma concorrente, razão do direito e do dever de informar. 0 Administrado deve ser informado, ouvido e obter explicações por ser um agente colaborador da administração. Justifica-se o dever de informar da Administração Pública, porque esta é modelada para o Estado Democrático, de acordo com a Constituição Federal de 1988, e por isso é que é pautada em Princípios, por exemplo, o da Publicidade e o da Transparência, sendo concretizado, dessa forma, através do direito de Acesso à Informação dos órgãos públicos (MENDONÇA; FERREIRA, 2021, p. 57).

A decisão judicial em análise, ademais, segue a orientação consagrada no precedente do próprio Supremo Tribunal Federal, nos autos da ADPF n 669-DF, Relator Ministro Luís Roberto Barroso, que proibiu que a União Federal venha a veicular qualquer publicidade institucional direcionada a induzir ou instigar a população brasileira ao retorno normal às suas atividades, paralisadas em razão do Coronavírus, buscando- 
se densificar, além dos direitos fundamentais à vida e à saúde das pessoas, o direito fundamental à informação da população (COURA e SOUSA, 2021, p. 135-159).

Sob a ótica da Lei no 13.655 , de 25 de junho de 2018, mencionada no capítulo anterior, a determinação judicial de adoção de medidas de publicidade e transparência de dados, já adotadas anteriormente pela União Federal, por meio do Ministério da Saúde, atende às diretrizes normativas do marco jurídico aludido, notadamente a necessidade de decisões judiciais que não se baseiem somente em valores e princípios jurídicos abstratos e, portanto, indiquem as consequências práticas das decisões (artigo 20), bem como considerem os obstáculos e dificuldades reais da gestão pública no cumprimento de políticas públicas (artigo 22).

Isto porque, na decisão mencionada, vale reforçar, o Supremo Tribunal Federal conferiu efetividade à Constituição brasileira de 1988, notadamente aos direitos fundamentais à vida, à saúde e a informação dos cidadãos (artigos 5ㅜㅜ, inciso XXXIII, 6o e 196 a 200), concretizando-os, à luz do contexto subjacente e das informações do caso vertente, sem impor medidas impraticáveis, desproporcionais ou irrealizáveis ao Ministério da Saúde, tendo em vista que a decisão em exame determinou o retorno à forma de divulgação anterior, portanto, plenamente factível e realizável pelo Poder Executivo Federal.

Além disso, a decisão em análise também dá concretude ao direito fundamental à informação e à publicidade pertinente às ações, políticas públicas de saúde lastreadas na ciência e nos dados e indicadores técnicos referentes à Covid-19, nos termos da aludida Lei no 13.979/2020 (BUSSINGUER e SOUSA, 2021, p. 397-424). Cuida-se, pois, da publicidade e do acesso às informações qualificadas diretamente relacionadas à preservação da vida e da saúde das pessoas.

Pelos argumentos jurídicos mencionados, a decisão judicial em exame realiza, concretamente, o princípio da separação e independência das funções estatais, constituindo, portanto, intervenção razoável, proporcional e equilibrada, do Supremo Tribunal Federal, em atos de competência do Poder Executivo Federal, de modo a garantir a transparência real das políticas públicas setoriais de saúde para o enfretamento à Covid-19 no Brasil, visando proteger os direitos fundamentais à vida, à saúde e à informação dos cidadãos, em última análise, a tutela do direito fundamental à boa administração dos serviços públicos de saúde, que devem ser eficientes, eficazes e transparentes, em todas as fases da sua execução.

\section{Considerações Finais}

Cabe aos Poderes Executivo e Legislativo, na forma da Constituição brasileira de 1988 (artigo 84, inciso XI), precipuamente, a formulação, o planejamento, a orçamentação e a execução das políticas públicas de saúde, cabendo ao Poder Judiciário o controle de constitucionalidade e legalidade das mesmas. 
Assim, em princípio, seria vedado ao Poder Judiciário determinar a obrigatoriedade, a forma e o conteúdo da publicidade pertinente às políticas públicas de saúde para o enfretamento ao Coronavírus, incluindo-se, nesta perspectiva, o conteúdo e a forma de veiculação à população dos dados e informações pertinentes à pandemia, eis que se cuida de atividade tipicamente administrativa, cuja gestão cabe ao Chefe do Poder Executivo Federal, no exercício da direção superior da administração pública, podendo contar com o auxílio dos seus Ministros, nos termos da mesma Constituição brasileira de 1988 (artigo 84, inciso II).

Destarte, no contexto da Covid-19, a separação das funções estatais, diante da Constituição da República Federativa do Brasil de 1988, significa o exercício prudente, razoável, proporcional, equilibrado e moderado, das respectivas funções especializadas pelos órgãos constitucionalmente autônomos, em harmonia com os demais núcleos orgânicos de funções estatais, de modo a realizar, de maneira eficiente e eficaz, a formulação, planejamento, orçamentação, implementação e controle das políticas públicas de saúde pública, concretizando o direito fundamental à boa administração pública, na perspectiva do direito fundamental à saúde, a partir da prestação adequada dos serviços públicos de saúde, que pressupõe ações públicas visíveis e transparentes, em consonância com as diretrizes da comunidade científica.

Neste sentido, a não observância desses parâmetros constitucionais para a eficiente e eficaz prestação dos serviços públicos de saúde viabiliza e justifica constitucionalmente a intervenção, razoável e proporcional, do Poder Judiciário, no controle das políticas públicas de saúde, de modo a conformá-las aos limites e possibilidades fixados na Constituição da República de 1988, com vistas a resguardar o direito fundamental à saúde dos cidadãos, diante da crise pandêmica da Covid-19, sem que se tenha violação ao princípio constitucional da separação das funções estatais previsto no artigo 2o da Constituição da República Federativa do Brasil de 1988.

Pelos argumentos jurídicos mencionados, a decisão judicial em exame realiza, concretamente, o princípio da separação e independência das funções estatais, constituindo, portanto, intervenção razoável, proporcional e equilibrada, do Supremo Tribunal Federal, em atos do Poder Executivo Federal, de modo a garantir a transparência real das políticas públicas setoriais de saúde para o enfretamento à Covid-19 no Brasil, visando proteger os direitos fundamentais à vida, à saúde e à informação dos cidadãos, em última análise, a tutela do direito fundamental à boa administração dos serviços públicos de saúde, que devem ser eficientes, eficazes e transparentes, em todas as fases da sua execução.

\section{Referências Bibliográficas}

BRASIL. Constituição da República Federativa do Brasil de 1988. Disponível em:<http://www.planalto.gov.br/ccivil_03/constituicao/constituicao.htm>. Acesso em 23 set. 2020. 
BRASIL. Lei $\quad n^{\underline{0}} \quad 13.979 / 2020 . \quad$ Disponível em: <http://www.planalto.gov.br/ccivil_03/_ato2019-2022/2020/lei/L13979.htm>. Acesso em 23 set. 2020.

BRASIL. Lei $n^{o}$ 13.655/2018. Disponível em:<http://www.planalto.gov.br/ccivil_03/_ato2015-2018/2018/lei/L13655.htm>. Acesso em 30 set. 2020.

BRASIL. Supremo Tribunal Federal. Arguição de Descumprimento de Preceito Fundamental $n^{\circ}$ 669-DF. Relator Ministro Luis Roberto Barroso. Disponível em <http://www.stf.jus.br/arquivo/cms/noticiaNoticiaStf/anexo/ADPF669ca utelar.pdf>. Acesso em 06 jul. 2021.

BRASIL. Supremo Tribunal Federal. Arguição de Descumprimento de Preceito Fundamental $n^{\circ}$ 690-DF. Relator Ministro Alexandre de Morais. Disponível em <http://www.stf.jus.br/arquivo/cms/noticiaNoticiaStf/anexo/ADPF690ca utelar.pdf>. Acesso em 06 jul. 2021.

BUSSINGUER, Elda Coelho de Azevedo e SOUSA, Horácio Augusto Mendes de. Vida e morte diante do inimigo invisível: exame da constitucionalidade dos protocolos de escolha dos pacientes do Coronavírus que terão preferências em leitos escassos, à luz dos direitos fundamentais à vida e à saúde. In: Direitos fundamentais na perspectiva da democracia interamericana. ALVITES, Elena; POMPEU, Gina Marcilio; SARLET, Ingo Wolfgang. (Orgs). Porto Alegre, RS: Editora Fundação Fênix, 2021, p. 397-424. Disponível em: <https://www.fundarfenix.com.br>. Acesso em: 11 out. 2021.

BUSSINGUER, Elda Coelho de Azevedo e SOUSA, Horácio Augusto Mendes de. Exame da constitucionalidade dos gastos públicos com medicamentos sem eficácia científica comprovada: o uso da cloroquina e da hidroxicloroquina para o tratamento do Coronavírus no Brasil. In: Direitos Fundamentais e Políticas Públicas. Organizadores Robinson Tramontina, Elda Coelho de Azevedo Bussinguer e Bruno Lorenzetto. Joaçaba: Editora Unoesc, 2020, p. 265-294.

CANOTILHO, José Joaquim Gomes. Direito Constitucional e Teoria da Constituição. $3^{\text {a }}$ ed. Coimbra: Almedina, 1998.

COURA, Alexandre de Castro; SOUSA, Horácio Augusto Mendes de. As tensões existentes entre constitucionalismo e democracia e suas repercussões na concretização de direitos fundamentais: estudo de caso à luz da decisão proferida pelo Supremo Tribunal Federal na ADPF no 669-DF. Interesse Público IP, Belo Horizonte, ano 23, n. 129, p. 135-159, set./out. 2021.

FAGUNDES, Miguel Seabra. $O$ controle dos atos administrativos pelo Poder Judiciário. $7^{\text {a }}$ ed. Rio de Janeiro: Forense, 2006.

FIORAVANTI, Maurizio. Constitución. De la Antigüedad a Nuestros Días. Traducción de Manuel Martinez Neira. Madrid: Editorial Trotta, 2001. 
FERRAJOLI, Luigi. La democracia a través de los derechos. El constitucionalismo garantista como modelo teórico y como proyecto político. Traducción de Perfecto Andrés Ibáñez. Madrid: Editorial Trotta, 2014.

FREITAS, Juarez. Direito fundamental à boa administração pública. $3^{\mathrm{a}}$ ed. São Paulo: Malheiros, 2014.

GARCÍA DE ENTERRÍA, Eduardo. As transformações da justiça administrativa: da sindicabilidade restrita à plenitude jurisdicional. Uma mudança de paradigma? Tradução de Fábio Medina Osório. Belo Horizonte: Fórum, 2017.

JULIOS-CAMPUZANO, Alfonso de. La utopía constitucional y la sociedad abierta. "Una mirada crítica a los populismos". In: JULIOS-CAMPUZANO, Alfonso de (Coord.). Constitucionalismo. Un modelo jurídico para la sociedad global. Tradução de Alfonso de Julios Campuzano. Espanha: Editorial Aranzadi, 2019, p. 499-550.

JULIOS-CAMPUZANO, A. DE. Nuevos horizontes de los derechos humanos: la crisis de la modernidad jurídica en la sociedad tecnológica. Revista de Direitos e Garantias Fundamentais, v. 19, n. 3, p. 11-46, 29 dez. 2018.

MARQUES NETO, Floriano de Azevedo e FREITAS, Rafael Véras de. Comentários à Lei no 13.655/2018 (Lei de Segurança para a Inovação Pública). Belo Horizonte: Fórum 2019.

MEDAUAR, Odete. O Direito Administrativo em Evolução. 2ª ed. São Paulo: Revista dos Tribunais, 2003.

MENDONÇA, M. L. C. de A. e; FERREIRA DE SOUSA STEIN, F. P. Lei de Acesso à Informação e ao Controle Social na Administração Pública federal. Revista Digital de Direito Administrativo, [S. l.], v. 8, n. 2, p. 49-67, 2021. Disponível em: https://www.revistas.usp.br/rdda/article/view/179143. Acesso em: 17 dez. 2021.

MOLAS, Isidre. Derecho Constitucional. 4aa ed. Madrid: Editorial Tecnos, 2008.

MORAIS, Jose Luis Bolzan de. As crises do Estado e da Constituição e a transformação espaço-temporal dos Direitos Humanos. 2 ${ }^{\underline{a}}$ ed. Porto Alegre: Livraria do Advogado, 2011.

MOREIRA NETO, Diogo de Figueiredo. O Direito Administrativo no século XXI. Belo Horizonte: Fórum, 2018.

MOREIRA NETO, Diogo de Figueiredo. Novas mutações juspolíticas. Belo Horizonte: Fórum, 2016.

MOREIRA NETO, Diogo de Figueiredo. Relações entre poderes e democracia: crise e superação. Belo Horizonte: Fórum, 2014.

MOREIRA NETO, Diogo de Figueiredo. Mutações do Direito Público. Rio de Janeiro: Renovar, 2006. 
MORÓN, Miguel Sánches. Derecho Administrativo: parte general. 4aㅡ ed. Madrid: Editorial Tecnos, 2008.

OTERO, Paulo. Direito do procedimento administrativo. Coimbra: Almedina, 2019. v. I.

SANTOS, Boaventura de Sousa. A cruel pedagogia do vírus. Coimbra: Almedina. 2020.

SOUSA, Horácio Augusto Mendes de. Estado Constitucional transformado pela governança por standards e indicadores: estudo de caso no direito brasileiro à luz da decisão proferida pelo Supremo Tribunal Federal na ADPF no 669DF. In: Conexões Estado, Direito e Tecnologia. José Luiz Bolzan de Morais (Org.). Vitória: FDV publicações, 2020, p. 63-102. 